\title{
The evaluation of postural characteristics in rehabilitation professionals and its effect on pain, quality of life, and sleep level
}

\author{
(D)Ayça Uran Şan, ĐÜmüt Güzelküçük, (DArif Kenan Tan \\ Gaziler Physical Therapy and Rehabilitation Training and Research Hospital, Department of Physical Medicine and Rehabilitation, Ankara, Turkey
}

Cite this article as: Uran Şan A, Güzelküçük Ü, Tan AK. The evaluation of postural characteristics in rehabilitation professionals and its effect on pain, quality of life, and sleep level. J Health Sci Med 2021; 4(5): 716-721.

\begin{abstract}
Aim: Rehabilitation professionals play a primary role in patients' medical procedures, leaving them in long-term, fixed, and sometimes less than optimal body positions, leading to musculoskeletal disorders in individuals. This study aims to assess the postural characteristics of the rehabilitation professionals, investigate the effects on pain, quality of life, sleep levels, and identify possible risk factors.

Material and Method: Our study had 105 participants and was performed as a prospective, cross-sectional study. The demographic information of the individuals included in the study, whether they have any pain complaints related to the musculoskeletal system; if any, its localization and sleep level were evaluated. Participants were administered the Visual Analogue Scale (VAS) and the Employee Quality of Life Scale. The postural status was assessed using the Corbin Posture Scale.

Results: It was detected that the participants with higher Corbin Posture Scale scores had more severe pain levels assessed by VAS score (p:0.000, r:0.803), longer duration of musculoskeletal pain (p:0.000, r:0.456), and shorter daily sleep duration time (p:0.000,r:-0.424) as a result of our study.

Conclusion: Postural dysfunction in rehabilitation professionals leads to many medical problems, especially musculoskeletal pain, high analgesic consumption, and sleep disturbances. As a result, there may be a reduction in quality of life. Preventive postural exercise programs can also be beneficial.
\end{abstract}

Keywords: Rehabilitation, healthcare professionals, posture

\section{INTRODUCTION}

The concept of posture is defined as the positioning of each body part in the most appropriate position to the adjacent segment and the whole body. Depending on immobility and occupational demands, long-term fixation of the body in a particular position during work can cause severe postural problems (1). One of these problems is undoubtedly musculoskeletal pain. Individuals may have painful spasms and regional muscle weakness as a result of poor posture. Since the rehabilitation professionals play a primary role in various medical procedures, such as conducting physical examinations of patients, caregiving, providing hygiene, positioning, monitoring vital functions, taking blood samples, applying medications, implement of physical therapy modalities, planning and manufacturing orthotic materials, preparation medical documents and reports; they remain in fixed and sometimes non-optimal positions of the body, which can lead to diseases of the musculoskeletal system for a long time. There are few studies in literature which determines the musculokeletal complaints in rehabilitation professionals $(2,3,4)$. In a study by Islam et al. (2) it was revealed that ninety-five percent of the participants complained of work related pain and most of the participants reported pain in the lower back $(n=84)$ followed by upper back $(n=71)$ and neck $(n=66)$ . In another study by Alnaser et al. (3) it was detected that the lower back and muscle spasm were the most common body injured area among the physical therapists and manual therapy techniques and patient transfers were most common activities associated with injuries. It was concluded in a study by Devreux et al. (4) that the musculoskeletal disorders expressed by rehabilitation staff in the area of Jeddah appeared to be strongly related to the level of over-commitment in work and the main symptoms were back pain and generalized myalgia which were severe 
enough to lead to sick leave and medical consultations. According to our knowledge, this is the first study which determines the postural characteristics in rehabilitation professionals. This study also aims to evaluate the effects of postural characteristics on pain, quality of life, and sleep levels in rehabilitation professionals. The study results will be used to guide protective measures for health personnel working in the area concerned.

\section{MATERIAL AND METHOD}

Our study was performed as a prospective and crosssectional study in a tertiary rehabilitation center. All procedures were carried out in accordance with the ethical rules and the principles of the Declaration of Helsinki. The study was approved by Ankara City Hospital No. 1 Clinical Researchs Ethics Committee (Date: 19.08.2020, Decision No: E1/1030/2020) and all participants signed the informed consent form. Inclusion criteria for the study were being aged between 18 and 65 years and working as a rehabilitation professional regardless of gender. Exclusion criteria were defined as having major general health problems or refusing to participate the study.

The demographic information (age, gender, height, weight, body mass index, etc.) of the participants enrolled in the study was recorded. Additionally; the number of patients treated per day, the number of years worked, weekly hours of work, and daily hours of work was calculated. It was examined whether the participants had any complaints of musculoskeletal pain; if any, in which body part they described the most severe pain and how long the pain had been present. The Visual Analogue Scale (VAS) score was used to assess the subjects' pain intensity level. This scale consists of a 10 points line drawn on a horizontal or vertical axis with scores ranging from " 0 points" for "no pain" to "10 point" for "worst pain". Participants were asked to score or mark the level that corresponded to the severity of their pain (5). We also evaluated participant's status of consulting a doctor, medical diagnosis, the types of treatments they received, and analgesic consumption per week. Participants' sleep disturbances and daily sleep duration (hours) were also examined.

The Professional Qualitiy of Life Scale is an instrument consisting of 30 items in aim to evaluate participants' positive and negative experiences that may arise from their job characteristics. The participants were asked to assign a score between 0 and 5 for each item on the scale. Although the total score is obtained as a result of these responses; the score of the "job satisfaction subscale" is obtained as a result of the responses to the first ten questions, the score of the "burnout subscale" is the result of the responses to the second 10-question section. As a result of the responses to the third 10-question section, the score of the "compassion fatigue subscale" was calculated (6).
The Corbin Posture Scale is a postural assessment scale that evaluates the inclination of the head in different directions, the shape of the dorsal region, the presence of scapula and shoulder protraction, the signs of scoliosis, kyphosis, lordosis, whether there is a difference in the height of the two shoulders and hips, the sagging status in the abdominal region, the presence of gibbosity, genu recurvatum, and the level of anterior balance by assigning a score between 0-3 (7).

Statistical analyses were performed using SPSS version 16 software. The parameters of mean, standard deviation, minimum, and maximum values were defined. The Kolmogorov-Smirnov test was used to determine whether the obtained parameters conformed to a normal distribution. Independent samples $t$ test was used to compare the parameters between gender groups. While investigating the associations between non-normally distributed or ordinal variables, the correlation coefficients $(\mathrm{r})$ and their significance $(\mathrm{p})$ were calculated using the Spearman test. A probability value of $\mathrm{p}<0.05$ was considered statistically significant.

\section{RESULTS}

The study included 105 healthcare professionals working in the field of rehabilitation. $66.66 \%$ of participants were female $(n=70), 33.33 \%$ were male $(n=35) .9 .5 \%$ of the participants included in our study were physicians $(\mathrm{n}=10), 31.4 \%$ were nurses $(\mathrm{n}=33), 15.2 \%$ were physiotherapists $(\mathrm{n}=16), 12.4 \%$ were orthotic and prosthetic technician $(n=13), 9.5 \%$ were secretaries $(n=10)$ and $21.9 \%$ were clinical support staff $(n=23)$. The mean age of the participants was $38.82 \pm 0.88$. The average working time of the healthcare professionals was $15.94 \pm 0.87$ years, the average weekly working duration was $41.30 \pm 0.42$ hours, and the daily working time was $8.17 \pm 0.11$ hours. The mean number of patients caring during the day was found to be $10.62 \pm 0.57$ (Table 1).

\begin{tabular}{|lc|}
\hline Table 1. The Socio-demographic characteristics of the participants & $\begin{array}{c}\text { Mean } \pm \text { Standart } \\
\text { deviation }\end{array}$ \\
\hline Age & $38.82 \pm 0.88$ \\
Body mass index $\left(\mathrm{kg} / \mathrm{m}^{2}\right)$ & $25.33 \pm 0.36$ \\
Years of experience & $15.94 \pm 0.87$ \\
Weekly working time (hours) & $41.30 \pm 0.42$ \\
Daily working time(hours) & $8.17 \pm 0.11$ \\
Number of patients cared for per day & $10.62 \pm 0.57$ \\
Gender & $\mathbf{n}(\%)$ \\
Female & $70(66.66 \%)$ \\
Male & $35(33.33 \%)$ \\
Job Groups & $\mathbf{n}(\%)$ \\
Physician & $10(9.5 \%)$ \\
Nurse & $33(31.4 \%)$ \\
Physiotherapist & $16(15.2 \%)$ \\
Orthotic-prosthetic technician & $13(9.5 \%)$ \\
Medical secretary & $10(21.9 \%)$ \\
Total number of participants $\mathrm{n}=105$ & \\
\hline
\end{tabular}


While $86.7 \%(\mathrm{n}=91)$ of participants described pain related to the musculoskeletal system, $13.3 \%(n=14)$ reported no pain in any part of their body. $13.3 \%(\mathrm{n}=14)$ of the subjects have described the cervical region, $1 \%(\mathrm{n}=1)$ the thoracic region, $10.5 \%(\mathrm{n}=11)$ the dorsal region, $31.4 \%(\mathrm{n}=33)$ the lumbar region, $1 \% \mathrm{i}(\mathrm{n}=1)$ the sacral region, $13.3 \%(\mathrm{n}=14)$ the shoulder region, $1.9 \%(\mathrm{n}=2)$ the elbow region, $3.8 \%$ $(\mathrm{n}=4)$ the hand/wrist region, $\% 1(\mathrm{n}=1)$ the hip region, $8.6 \%$ $(n=9)$ the knee region and $1 \%(n=1)$ the foot/ankle region as the of most severe pain location. The participants' mean pain duration was found as $43.20 \pm 4.60$ months. $46.7 \%$ $(n=49)$ of participants consulted a doctor due to their musculoskeletal pain, $23.8 \%(n=25)$ of the participants stated that they wanted to consult a doctor but could not yet, $29.5 \%(n=31)$ reported that they did not need medical support. The diagnosis of the rehabilitation professionals who had consulted a doctor were osteoarthritis (17.1\%) $(\mathrm{n}=18)$, rheumatoid arthritis $(1 \%)(\mathrm{n}=1)$, disc herniation $(14.3 \%)(\mathrm{n}=15)$, meniscal degeneration $(2.9 \%)(\mathrm{n}=3)$, tendinitis $(7.6 \%)(\mathrm{n}=8)$, sacroiliitis $(1 \%)(\mathrm{n}=1)$, scoliosis $(1.9 \%)(n=2)$, myofascial pain syndrome $(1 \%)(n=1)$ (Table 2). $46.7 \%$ of healthcare professionals reported that they did not receive any treatment for their musculoskeletal complaints, $21 \%(n=22)$ of participants reported that they used analgesics, $20 \%(\mathrm{n}=21)$ received exercise therapy, and $12.4 \%(\mathrm{n}=13)$ reported that they received a physiotherapy program. The mean VAS score of the participants was found to be $5.81 \pm 0.32$. It was found that the mean number of analgesic consumption by the participants was $7.36 \pm 0.68$ per week. It was found that $54.3 \%(n=57)$ of the health professionals who participated in our study had sleep problems. The average sleep duration of the participants was found to be $6.60 \pm 0.13$ hours per day. The mean Corbin Posture Scale score used to examine the postural dysfunction of the individuals included in our study was found to be $5.59 \pm 0.26$. The total mean score of the Professional Quality of Life Scale, which was used to assess the participants' quality of life was $76.31 \pm 1.41$. The average score of the "Job satisfaction" subscale was $23.83 \pm 0.54$, the mean score of the "burnout" subscale was $27.89 \pm 0.55$, and the mean score of "compassion fatigue" subscale was $24.58 \pm 0.54$ (Table 3 ). The comparision of patient characteristics according to gender revealed that there was a statistically significant difference in age (p:0.039) and body mass indeks $(\mathrm{p}<0.001)$ parameters between female and male groups; no statistically significant difference was detected in other parameters (Table 4).

\begin{tabular}{|lc|}
\hline \multicolumn{2}{|l|}{ Table 2. The pain characteristics of the participants } \\
\hline Presence of musculoskeletal pain & $\mathbf{n}(\%)$ \\
\hline Yes & $91(86.7 \%)$ \\
No & $14(13.3 \%)$ \\
Pain localization & $\mathbf{n}(\%)$ \\
Cervical region & $14(13.3 \%)$ \\
Thoracic region & $1(1 \%)$ \\
Dorsal region & $11(10.5 \%)$ \\
Lumbar region & $33(31.4 \%)$ \\
Sacral region & $1(1 \%)$ \\
Shoulder region & $14(13.3 \%)$ \\
Elbow region & $2(1.9 \%)$ \\
Hand/Wrist region & $4(3.8 \%)$ \\
Hip region & $1(1 \%)$ \\
Knee region & $9(8.6 \%)$ \\
Foot/Ankle region & $1(1 \%)$ \\
Diagnoses of participants & $\mathbf{n}(\%)$ \\
Osteoarthritis & $18(17.1 \%)$ \\
Rheumatoid arthritis & $1(1 \%)$ \\
Disc herniation & $15(14.3 \%)$ \\
Meniscus degeneration & $3(2.9 \%)$ \\
Tendinitis & $8(7.6 \%)$ \\
Sacroiliitis & $1(1 \%)$ \\
Scoliosis & $2(1.9 \%)$ \\
Myofascial pain syndrome & $1(1 \%)$ \\
\hline &
\end{tabular}

\begin{tabular}{|c|c|}
\hline & $\begin{array}{l}\text { Mean } \pm \text { Standart } \\
\text { Deviation }\end{array}$ \\
\hline VAS value & $5.81 \pm 0.32$ \\
\hline Corbin Posture Scale Score & $5.59 \pm 0.26$ \\
\hline $\begin{array}{l}\text { The Professional Qualitiy of Life Scale } \\
\text {-Job Satisfaction subscale score }\end{array}$ & $23.83 \pm 0.54$ \\
\hline $\begin{array}{l}\text { The Professional Qualitiy of Life Scale } \\
\text {-Burnout subscale score }\end{array}$ & $27.89 \pm 0.55$ \\
\hline $\begin{array}{l}\text { The Professional Qualitiy of Life Scale } \\
\text {-Compassion fatigue subscale score }\end{array}$ & $24.58 \pm 0.54$ \\
\hline $\begin{array}{l}\text { The Professional Qualitiy of Life Scale } \\
\text {-Total score }\end{array}$ & $76.31 \pm 1.41$ \\
\hline
\end{tabular}

\section{Table 4. The comparision of patient characteristics between genders}

\begin{tabular}{|lccc|}
\hline & Female $(\mathbf{n}=\mathbf{6 7})$ Mean \pm SD & Male $(\mathbf{n}=\mathbf{3 8}) \mathbf{M e a n} \pm$ SD & $41.44 \pm 9.77$ \\
\hline Age & $37.68 \pm 8.32$ & $27.12 \pm 2.95$ & 0.039 \\
Body mass index $\left(\mathrm{kg} / \mathrm{m}^{2}\right)$ & $24.33 \pm 3.78$ & $16.94 \pm 9.01$ & 0.000 \\
Years of experience & $15.18 \pm 8.95$ & $41.86 \pm 4.14$ & 0.337 \\
Weekly working time (hours) & $40.98 \pm 4.45$ & $8.02 \pm 0.16$ & 0.319 \\
Daily working time (hours) & $8.25 \pm 1.44$ & $11.05 \pm 5.56$ & 0.208 \\
Number of patients cared for per day & $11.46 \pm 6.01$ & $35.10 \pm 41.65$ & 0.731 \\
Pain duration (month) & $47.80 \pm 49.82$ & $7.28 \pm 6.73$ & 0.187 \\
Analgesic consumption per week & $7.40 \pm 6.84$ & $5.23 \pm 3.73$ & 0.935 \\
VAS value & $6.14 \pm 3.03$ & $5.05 \pm 2.75$ & 0.204 \\
Corbin Posture Scale Score & $5.89 \pm 2.67$ & $75.39 \pm 17.01$ & 0.128 \\
The Professional Qualitiy of Life Scale -Total score & $76.83 \pm 12.96$ & $6.84 \pm 1.26$ & 0.627 \\
Sleep duration (hour/day) & $6.46 \pm 1.37$ & 0.165 \\
\hline
\end{tabular}


It was also detected that rehabilitation professionals with longer years of work had longer musculoskeletal pain duration ( $\mathrm{p}: 0.002, \mathrm{r}: 0.30$ ), had higher VAS scores (p:0.006, $r: 0.267)$, and greater consumption of analgesics per week ( $\mathrm{p}: 0.001, \mathrm{r}: 0.309)$. As the number of patients that the rehabilitation professionals deal with during the day had increased, it was found that their pain duration (p:0.000, r: 0.498), VAS score (p:0.000, $\mathrm{r}: 0.801$ ), and the number of analgesic consumption per week had an increment ( $\mathrm{p}: 0.000, \mathrm{r}: 0.720$ ). When the effect of rehabilitation professionals' postural status on other parameters were examined; it was revealed that the health professionals with higher Corbin Posture Scale scores were dealing with more patients (p:0.000, $\mathrm{r}: 0.636$ ) (Figure 1) had higher VAS scores (p:0.000, $\mathrm{r}: 0.803$ ) (Figure 2), longer pain durations (month) (p:0.000, r:0.456) (Figure 3), greater consumption of analgesics per week (p:0.000, r:0.608). Furthermore; a positive correlation was found between the Corbin Posture Scale score and the total score of the the Professional Quality of Life Scale scres ( $\mathrm{p}: 0.022$, $\mathrm{r}: 0.223)$. No statistically significant correleation was found in the occupational satisfaction subscale scores and the burnout subscale scores of the Professional Quality of Life Scale with other parameters. ( $p>0.05)$. However; a positive correlation was detected between this scale's compassion fatigue subscale score and the age of the healthcare professionals (p:0.047, r:0.195). It was also found that there was a significant reduction in sleep duration of participants who had deal with higher number of patients per day (p:0.000, r:-0.494); had longer duration of musculoskeletal pain, (p:0.000, r:0.383), had higher VAS scores ( $\mathrm{p}: 0.000, \mathrm{r}:-0.543$ ) and had higher Corbin Posture Scale scores (p:0.000,r:-0.424) (Figure 4).

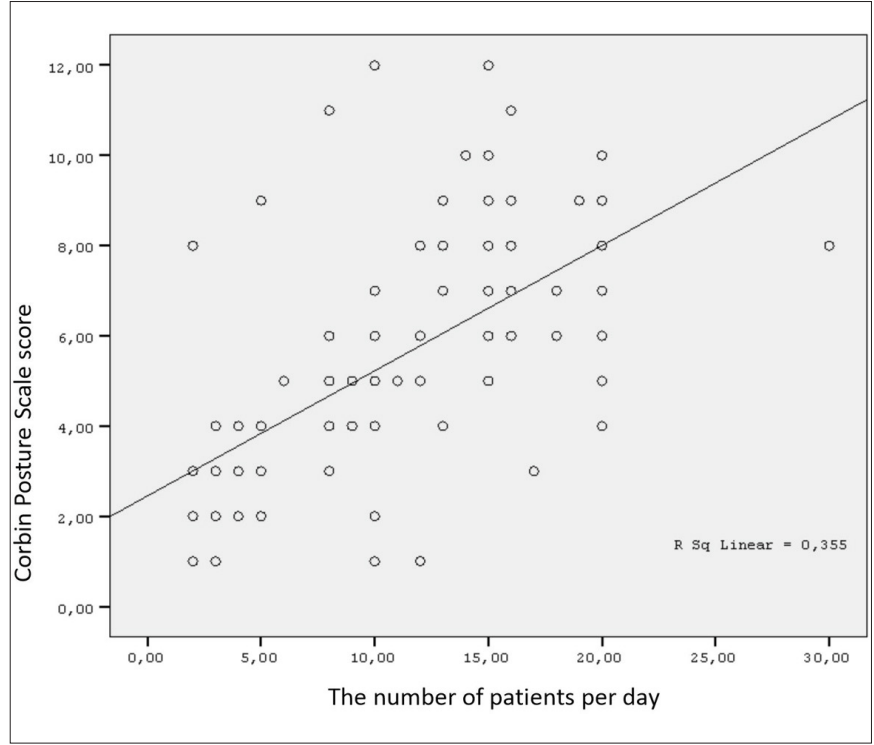

Figure 1. The correlation between Corbin Posture Scale scores and the number of patients cared for during the day

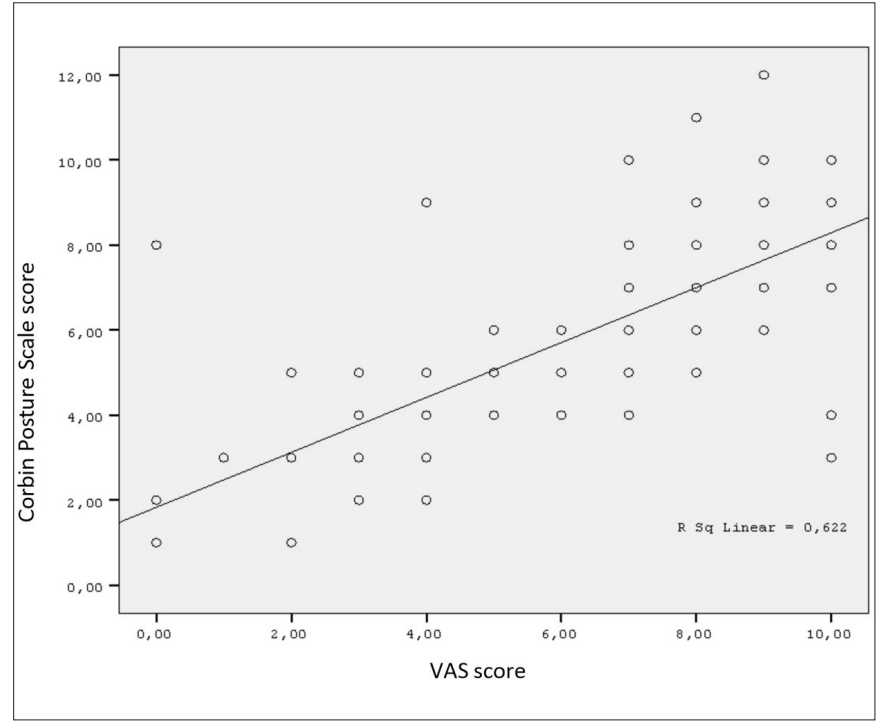

Figure 2. The correlation between Corbin Posture Scale scores and VAS scores

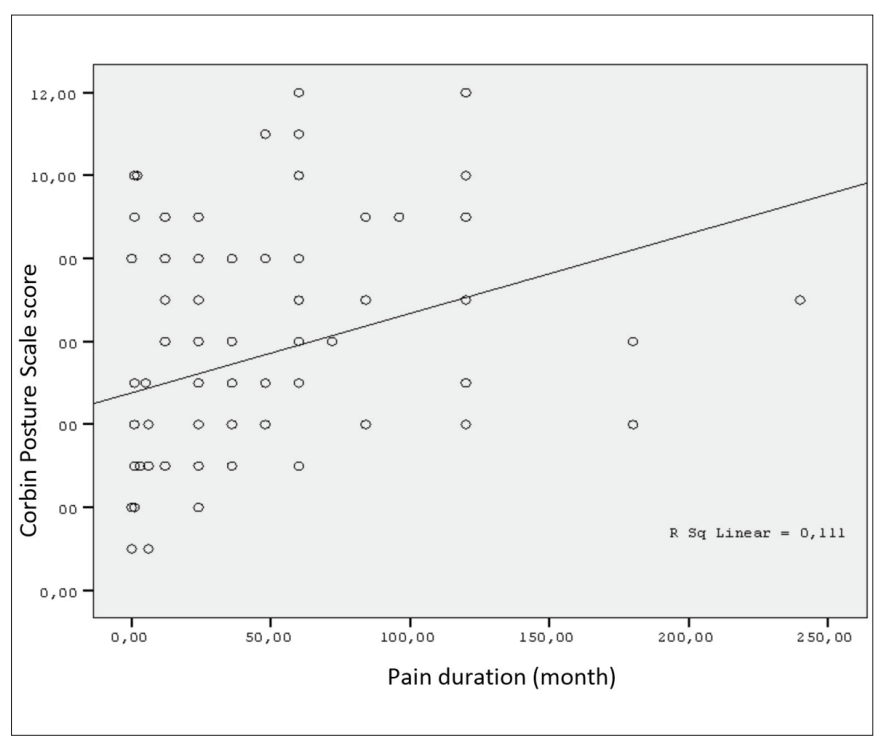

Figure 3. The correlation between Corbin Posture Scale scores and pain durations (months)

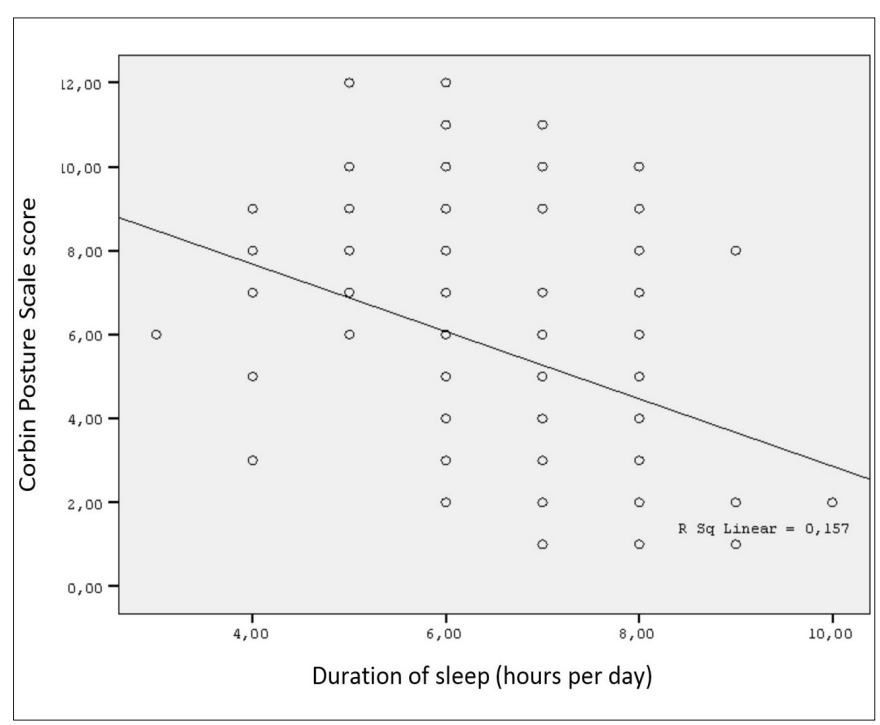

Figure 4. The correlation between Corbin Posture Scale scores and daily sleep durations (hours) 


\section{DISCUSSION}

The relationship between the postural status of rehabilitation professionals and the level of musculoskeletal pain was revealed in our study. The rehabilitation professionals with postural impairments were found to have more severe pain complaints, longer pain duration, and more analgesic consumption per week. It has been observed that this situation leads to a deterioration in the quality of life. In a study by Küçük et al. (8) that included 213 office workers, it was found that $48.4 \%$ of the participants worked in a static seated posture with the neck bent forward in the work environment. In addition, it was found that these individuals experienced spinal pain $6.57 \pm 7.11$ times per week, and concluded that the defined postural dysfunction may cause spinal pain more frequently in the participants.

In another study by Ribeiro et al. (9) which examines the musculoskeletal system problems of nurses according to their work lifes; it has been reported that the frequency of musculoskeletal system complaints had increased in participants who had longer years of work experience. Additionally; standing (48.8\%), forward bending of the trunk $(42.3 \%)$, trunk rotation $(40.6 \%)$, excessive use of force on hands and fingers (37.3\%), sitting (36.6\%), and repetitive arm movements (34.3\%) were defined as risky movements observed in participants during the work which may lead to musculoskeletal problems in the same study (9). The results of our study revealed that rehabilitation professionals who have been working for longer years had longer pain durations, higher VAS scores and more analgesic consumption per week.

Ezzatvar et al. (10) showed in their study, which evaluated the impact of physiotherapist workload on musculoskeletal pain, that participants who deal with more than 30 patients per week had higher levels of musculoskeletal pain. Similarly, we have found in our study that the rehabilitation professionals who deal with more patients during the day had longer pain durations, higher VAS scores, higher amount of analgesic consumption per week, and higher levels of postural dysfunctions. During the rehabilitation procedures such as performing physical examination of the patients, the administration of their medical treatments, the collection of blood and urine samples, the positioning, providing patient transfer, the application of physiotherapy techniques, the production of orthotics and prosthesis materials, the registration of medical documents; the rehabilitation professionals may have positioned in postures that are not appropriate for body biomechanics. As the number of patients dealt with during the day increases, the time spent in inappropriate postures of healthcare professionals also has an increment. As a result; it plays a role in the development of various posture disorders as dropped shoulder, increment in thoracic kyphosis, reduction in both cervical lordosis and lumbar lordosis.

In a study by Tolu et al. (11) (2019), which examined the musculoskeletal problems of anesthesiologists, it was reported that the musculoskeletal complaints of the participants were observed in the regions of low back (51.2\%), neck (42.3\%), knee (35.8\%), shoulder (29.3\%), foot/ankle (28.5\%), back (26\%), elbow (22\%), hip/thigh (19.5\%) and hand/wrist (14.6\%). In accordance with these findings, the rehabilitation professionals have described low back, neck, shoulder and back regions as the most painful localizations of their body in our study. Rehabilitation professionals usually keep their bodies in inappropriate, static, flexion postures for a long time to perform patients' rehabilitation procedures; as a result the formation of pathological muscle spasms and extra load transferring to joints may occur and this process also leads to musculoskeletal pain $(11,12)$.

In a study by Harrison et al. (13) the relationship between sleep level and musculoskeletal system problems has been revealed and it has been concluded that the severity of pain has a statistically significant positive correleation with sleep disorders. Similarly, it was detected that rehabilitation professionals with lower daily sleep durations have longer duration of musculoskeletal pain, and higher VAS scores in our study.

\section{CONCLUSION}

The results of our study revealed the effect of rehabilitation professionals' postural status on pain, sleep level, and quality of life. Postural disorders in individuals lead to many medical problems, including musculoskeletal pain, high analgesic consumption, and sleep disturbances. As a result, there may be a reduction in the quality of life. Therefore, it is of great importance to detect postural disorders of rehabilitation professionals as early as possible, follow up their musculoskeletal complaints for a long time, treat existing pathologies, and provide protective exercise programs in necessary conditions.

\section{ETHICAL DECLARATIONS}

Ethics Committee Approval: The study was approved by Ankara City Hospital No. 1 Clinical Researchs Ethics Committee (Date: 19.08.2020, Decision No: E1/1030/2020)

Informed Consent: All patients signed the free and informed consent form.

Referee Evaluation Process: Externally peer-reviewed. 
Conflict of Interest Statement: The authors have no conflicts of interest to declare.

Financial Disclosure: The authors declared that this study has received no financial support.

Author Contributions: All of the authors declare that they have all participated in the design, execution, and analysis of the paper, and that they have approved the final version.

\section{REFERENCES}

1. Tufan AD, Karabuğa B, Simay B, et al. Postür ve postür bozuklukları. Fizyoterapi Reh Derg 1996; 8: 1-10.

2. Islam MS, Habib MM, Hafez MA,et al. Musculoskeletal complaints among physiotherapy and occupational therapy rehabilitation professionals in Bangladesh. Work 2015; 50: 37986.

3. Alnaser MZ, Aljadi SH. Physical therapists with work-related musculoskeletal disorders in the State of Kuwait: A comparison across countries and health care professions. Work 2019; 63: 261-68.

4. Devreux ICN, Al-Awa B, Mamdouh K, et al. Relation of workrelated musculoskeletal disorders and over-commitment of rehabilitation staff in Saudi Arabia. Life Sci J 2012; 9: 781-85

5. Keele KD. The pain chart. Lancet $1948 ; 2: 6-8$.

6. Yeşil A, Ergün Ü, Amasyalı C, et al. Çalışanlar için yaşam kalitesi ölçeği Türkçe uyarlaması geçerlik ve güvenilirlik çalışması. Nöropsikiyatri Arşivi 2010; 47: 111-7.

7. Corbin C, Welk G, Corbin W, Welk K. Concepts of fitness and wellness: A comprehensive lifestyle approach. In: McGraw-Hill Companies, Incorporated; 2008.

8. Küçük F, Düzenli ÖS, Şenol H, Özkeskin M . Ofis çalışanlarında çalışma postürü, kas iskelet sistemi rahatsızlıkları, bel ağrısına bağlı özürlülük düzeyi ve sağlıkla ilgili yaşam kalitesinin incelenmesi. Ergoterapi ve Rehabilitasyon Derg 2018; 6: 135-44.

9. Ribeiro T, Serranheira F, Loureiro H. Work related musculoskeletal disorders in primary health care nurses. Appl Nurs Res 2017; 33: 72-7

10.Ezzatvar Y, Calatayud J, Andersen LL, Aiguadé R, Benítez J, Casaña J. Professional experience, work setting, work posture and workload influence the risk for musculoskeletal pain among physical therapists: a cross-sectional study. Int Arch Occupat Environment Health 2020; 93: 189-96.

11.Tolu S BB. Work-related musculoskeletal disorders in anesthesiologists: A cross-sectional study on prevalence and risk factors. Ann Med Res 2019; 26 :1406-14.

12.Szeto GP, Cheng SW, Poon JT, Ting AC, Tsang RC, Ho P. Surgeons' static posture and movement repetitions in open and laparoscopic surgery. J Surg Res 2012; 172: 9-31.

13. Harrison L, Wilson S, Munafò MR. Exploring the associations between sleep problems and chronic musculoskeletal pain in adolescents: a prospective cohort study. Pain Res Manag 2014; 19: 139-45. 